\title{
Efecto del manejo del suelo sobre la diversidad de endomicorrizas.
}

\author{
Faggioli, Valeria ${ }^{1}$ \\ ${ }^{1}$ INTA EEA Marcos Juarez \\ Conferencia dictada en el marco de la XI Reunión Nacional Científico-Técnica de Biología de Suelos. \\ Corrientes (Argentina)- Octubre de 2017
}

Los hongos formadores de micorrizas arbusculares (HFMA, phylum Glomeromycota) son habitantes autóctonos de un gran rango de ecosistemas naturales y antrópicos. Son simbiontes obligados que necesitan del aporte de fotoasimilados vegetales para sus funciones vitales y establecen simbiosis con aproximadamente el $80-90 \%$ de las especies vegetales. Forman parte de procesos clave en el ecosistema tales como la conservación de carbono y mantenimiento de la estructura del suelo, mejoras en la nutrición y sanidad vegetal, aumento en la tolerancia a déficit hídrico, entre otros. Aunque pueden persistir en el suelo durante un cierto tiempo, son muy sensibles a los disturbios de su hábitat. Las prácticas de manejo realizadas en los agroecosistemas atentan de manera directa e indirecta a estos organismos. El efecto directo se refiere a la pérdida de especies de HFMA, mientras que el efecto indirecto implica la pérdida de funciones que dichas especies llevaban a cabo. Los sistemas de producción agrícola representan una gran alteración de los ambientes naturales. Entre las prácticas de manejo de mayor impacto sobre los HFMA se puede mencionar en primer lugar la sustitución de la vegetación nativa por especies introducidas y mejoradas genéticamente, el uso de pesticidas y fertilizantes, el monocultivo, la remoción del suelo y los barbechos prolongados. Sería posible pensar, entonces, que a mayor tiempo de adopción de la agricultura, mayor será el impacto sobre estos organismos del suelo. El objetivo de este trabajo fue estudiar la diversidad de HFMA en sistemas agrícolas con diferente historial de uso del suelo mediante identificación de esporas y técnicas moleculares. Se realizó un muestreo en 126 lotes de soja correspondientes a zonas de historial agrícola, mixto, y de reciente deforestación de las sierras cordobesas. En primer lugar, se cuantificó el nivel de micorrización de las raíces de soja y la infectividad micorrícica de los lotes y se correlacionaron con variables medidas en el suelo y en el cultivo. Se observó que en todos los sitios muestreados las plantas estaban colonizadas por HFMA, pero en menor medida en suelos arenosos y bien provistos de fósforo (P). La misma tendencia se observó con el grado de infectividad micorrícica. Esta variable se correlacionó positivamente con el carbono (C), arcilla y agua del suelo, y con la acumulación de materia seca y P de las plantas de soja. Posteriormente se analizó la estructura de las comunidades nativas de HFMA mediante identificación taxonómica de esporas (suelo) y por secuenciación del gen 18S SSU rRNA (suelo y raíces). En total se identificaron 36 especies de HFMA pertenecientes a 8 familias de Glomeromycota: Ambisporaceae, Acaulosporaceae, Claroideoglomeraceae, Diversisporaceae, Entrophosporaceae, Gigasporaceae and Glomeraceae. Las especies más frecuentes fueron: Acaulospora scrobiculata, Claroideoglomus etunicatum, Funneliformis mosseae y Glomus fuegianum. Las esporas mostraron una mayor riqueza y diversidad en los sitios recientemente deforestados. El P del suelo afectó en forma negativa a estos parámetros e impactó significativamente sobre la composición de las comunidades. Mediante secuenciación del gen 18S SSU rRNA se observó que las comunidades de HFMA del suelo no difirieron entre las tres zonas de estudio y que el gradiente textural fue la variable más influyente. En las raíces, en cambio, la zona agrícola tuvo una comunidad de HFMA diferente a la hallada en las zonas mixta y de sierras. Este estudio pone en evidencia el efecto de la agricultura a largo plazo en la comunidad de Glomeromycota. Los cambios en los parámetros ecológicos de riqueza, diversidad y estructura de las comunidades autóctonas de la biota del suelo pueden alterar de manera irreversible funciones ecológicas claves para la sustentabilidad.

Palabras clave: Rizósfera, Diversidad, Ecosistemas agrícolas. 